\title{
EDUCATION FOR DIABETES SELF-MANAGEMENT IMPROVES QUALITY OF LIFE AND REDUCES HBA1C LEVELS IN PEOPLE WITH DIABETES
}

Florian Toti (1) Elvisa Sokoli (2) Diana Pema (1) Leonora Gjeta (1) Eliora Kulluri (2) Gazmend Bejtja (3)

(1) Service of Endocrinology University Hospital Center "Mother Theresa" Tirana /Albania

$\begin{array}{ll}\text { (2) Faculty of Psychology Tirana/ Albania } & \text { (3) Institute of Public Health Tirana/ Albania }\end{array}$

Objectives:

Knowing about patient's quality of life (QoL) is becoming increasingly important in delivering diabetes care and education. The purpose of our study was to estimate if the diabetes education improves patient QoL and reduces $\mathrm{HbA} 1 \mathrm{c}$ levels.

\section{Methods:}

\section{Conclusions:}

The study sample included diabetic patients who attended a 5-day educational sessions at the Service of Endocrinology in Tirana/Albania. Patients were evaluated regarding their QoL at baseline and 6 or 12 months after their hospitalization. The HbA1c was measured at baseline, 6 and 12 months later. The DQoL (Diabetes Quality of Life) measure was used to assess the subjective QoL. DQoL is a validated 46 items survey covering four areas of interest: satisfaction and impact of treatment, worry about the future effects of diabetes and worry about social issues, as well a single question about the general health. A satisfactory level is accepted as a transformed score $>60$.

The group consisted of 395 patients, 139 males (35\%) and 256 females, 97 (24.5\%) type 1 Diabetes, mean age $44.2 \pm 4.7$ years, diabetes duration $11.4 \pm 5.4$ years, treated with insulin in $45 \%$ of cases, with baseline HbA1c $9.1 \pm 1.67 \%$, having decreased respectively $8.5 \pm 1.1 \%$ at 6 months $(p<0.05)$ and $8.02 \pm 1.23 \%$ at 12 months after hospitalization $(p<0.001)$. DQoL at baseline was $56 \pm 4.5,68.2 \pm 5.7$ six months later and $75.1 \pm 3.5$ at 12 months interval $(p<0.05)$. The satisfaction with treatment and worry about the future were the most improved scores at six and 12 months after.
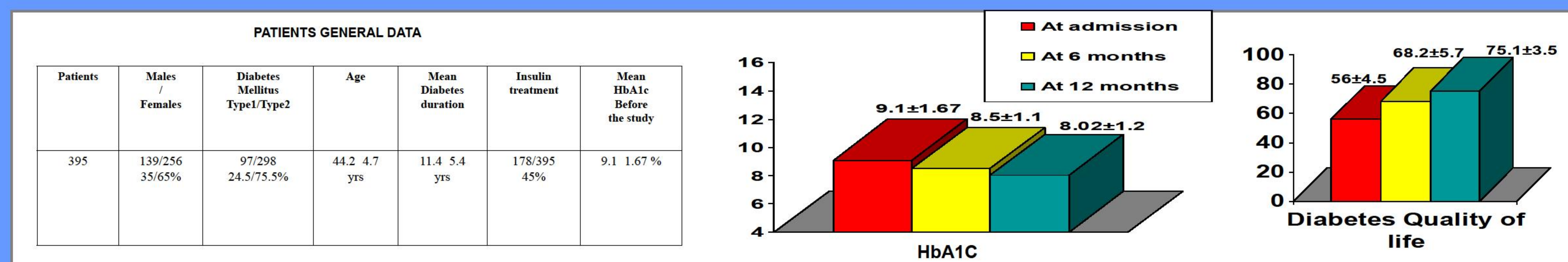

The education for self-management of the disease improves patients' Quality of Life as well their metabolic control.
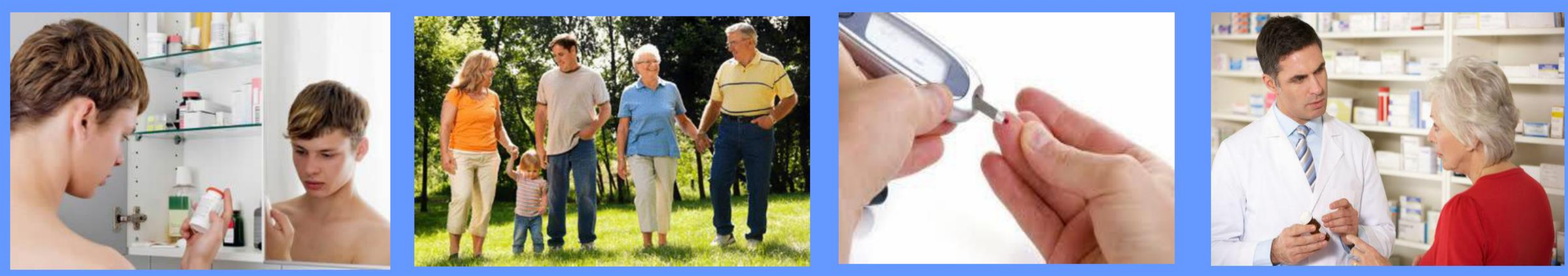